\author{
Cristhian Álvarez Zaldúa \\ cristhianalvarez77@hotmail.com \\ Facultad de Teología \\ Universidad Adventista de Bolivia \\ Cochabamba, Bolivia
}

Recibido: 20/04/2019

Aceptado: 01/06/2019

\title{
Resumen
}

Dentro del cristianismo existen muchas denominaciones religiosas que declaran ser la iglesia verdadera. Esto ha producido reacciones diversas entre las personas. Algunos afirman que no existe ninguna iglesia verdadera, pues las ven como simples negocios que buscan el dinero de la gente. Pero, ¿existe realmente una iglesia verdadera o no? Y si existe ¿cómo podemos identificarla y encontrarla? Para responder estas interrogantes, este artículo estudia lo que la Biblia enseña respecto a la iglesia verdadera.

Palabras clave: Ekklesia, iglesias, iglesia verdadera, remanente, disidencia

\begin{abstract}
Within Christianity there are many religious that claim to be the true church. This has caused diverse reactions among people. Some claim that there is no true church, as they see them as simply businesses looking for people's money. But, is there really a true church or not? And if there is, how can we identify and find it? To answer these questions, this article looks at what the Bible teaches about the true church.
\end{abstract}

Keywords: Ekklesia, churches, true church, remnant, dissidence 


\section{¿CUÁL ES LA IGLESIA VERDADERA?}

Dentro del cristianismo existen muchas denominaciones religiosas que declaran ser la iglesia verdadera. Aunque muchas de sus doctrinas y prácticas son contradictorias entre sí, cada una insiste en tener la verdad divina que el hombre necesita para su salvación. Esto ha generado reacciones diversas entre las personas. Algunos afirman que no existe ninguna iglesia verdadera, pues las ven como simples negocios que buscan el dinero de la gente. También están quienes dicen que como en todas las iglesias hay cosas buenas, entonces no importa en cuál se adore pues al final todas son diferentes caminos para llegar a Dios. ¿Cuál es la verdad de todo esto? ¿Existe realmente una iglesia verdadera o no? Y si existe ¿cómo podemos identificarla y encontrarla? Para responder estas interrogantes vamos a estudiar lo que la Biblia enseña respecto a la iglesia verdadera.

\section{La IGLESIA EN LA BIBLIA}

La palabra iglesia proviene del griego ekklēsía que significa "asamblea", “congregación”. ${ }^{1}$ La Septuaginta, traducción griega del Antiguo Testamento, ${ }^{2}$ usa ekklēsía como traducción del término hebreo qāhāl que significa "reunión", "asamblea"3 convocada para diversos propósitos (Dt 9:10; 10:4; $1 \mathrm{R} \mathrm{8:14;} 1 \mathrm{Cr}$ 13:2). ${ }^{4}$ En el contexto cristiano ekklēsía hace alusión a la asamblea de personas que han sido llamadas por Dios para salir del mundo y servirle.

Dios siempre ha tenido un pueblo. Por generaciones fueron los patriarcas y sus familias, luego de la familia de Abraham, formó al pueblo de Israel para que sea una bendición para todas las naciones (Gn 12:1-3). Esto se lograría por

${ }^{1}$ Johannes E. Louw y Eugene A. Nida, Greek-English Lexicon of the New Testament: Based on Semantic Domains, 2da ed., BibleWorks, version 10.0.4.114 (New York: United Bible Societies,

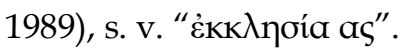

${ }^{2}$ Es la primera traducción del hebreo del Antiguo Testamento al griego. Realizada en Alejandría, Egipto, supuestamente por un grupo de setenta o setenta dos judíos entre los años 250 y 150 a. C. Para mayor información, ver F. F. Bruce, El canon de la Escritura [Barcelona: Publicaciones Andamio, 2014], 43-54.

${ }^{3}$ William L. Holladay, A Concise Hebrew and Aramaic Lexicon of the Old Testament: Based upon the Lexical Work of Ludwig Koehler and Walter Baumgartner, BibleWorks, version 10.0.4.114 (Leiden: Brill, 2000), s. v. "קָהָ".

${ }^{4} \mathrm{~A}$ menos que se indique lo contrario la versión que se utiliza en este trabajo es la Reina Valera (1995). 
compartir el conocimiento del Dios verdadero a las naciones paganas, y la esperanza del Mesías prometido. Es interesante que a Israel la Biblia lo llama "la congregación (ekklēsía) del desierto" (Hch 7:38). Sin embargo, cuando Israel no cumplió el rol asignado, Dios llamó a la iglesia del Nuevo Testamento, compuesta de judíos y gentiles (Mt 21:33-43; Ga 3:27, 28).

La iglesia no es una idea humana sino divina, por eso se la llama "la iglesia de Dios" (1 Co 1:2). Fue Jesús quien dijo: "Sobre esta roca edificaré mi iglesia" (Mt 16:18). ${ }^{5}$ Por tanto, la iglesia es importante porque fue fundada por Cristo, ella es su cuerpo y él su cabeza (1 Co 12:12-28; Ef 4:15; 5:23). Está conformada por aquellos que han recibido a Jesús como su Salvador (1 Co 1:1, 2), es el pueblo de Dios (1 P 2:9). Es descrita como "columna y defensa de la verdad" (1 Ti 3:15), y tiene la misión de anunciar al mundo el evangelio de salvación (Mt 28:18-20).

Cuando Jesús afirmó que "las puertas del Hades no prevalecerán contra ella" (Mt 16:18 [NVI]), estaba asegurando que la iglesia alcanzaría la victoria final sobre Satanás y sus instrumentos (Dn 12:1; Ap 7:9-17; 15:1-4). Por tal razón, el Apocalipsis presenta a los salvos triunfantes, alabando a Dios por toda la eternidad (Ap 19:1-8; 21:1-7; 22:1-5).

Sin lugar a dudas lo dicho hasta aquí es relevante, pero antes de continuar se deben resaltar otros aspectos sobre la iglesia. En primer lugar, ella no sería la más numerosa, pues comparada con aquellos que no aceptarían la verdad sería solo una "manada pequeña" (Lc 12:32). En segundo lugar, la Escritura rechaza la idea de que Dios acepta cualquier forma de adorarlo. En los días de Cristo varios grupos religiosos afirmaban servir a Dios. En una ocasión los fariseos le dijeron a Jesús que tenían a Dios como su padre (Jn 8:41), pues creían que Dios aprobaba su sistema religioso, pero Jesús lo desaprobó (Jn 8:44). Aunque hacían uso de las Escrituras, la habían tergiversado al colocar sus tradiciones por encima de la Palabra de Dios. Jesús les dijo: “¿Por qué también vosotros quebrantáis el mandamiento de Dios por vuestra tradición?... Hipócritas, bien profetizó de

${ }^{5} \mathrm{La}$ "roca" sobre la que fundamenta la iglesia no es Pedro, sino la verdad de que Cristo es el del Hijo del Dios viviente. Para más información, véase Cristhian Alvarez Zaldúa, "Es Pedro el fundamento de la iglesia", Revista adventista, ver http://revistaadventista.editorialaces.com/ index.php/2019/10/08/es-pedro-el-fundamento-de-la-iglesia/ (consultado: 9 de enero, 2020). 
vosotros Isaías, cuando dijo: 'Este pueblo de labios me honra, más su corazón está lejos de mí, pues en vano me honran, enseñando como doctrinas mandamientos de hombres'" (Mt 15:3, 7-9). Cualquier denominación religiosa que coloque las ideas humanas por encima de la autoridad de la Escritura o que la tergiverse, es un sistema religioso que Dios condena (2 P 3:15, 16), y ordena abandonarlo (2 Co 6:14-18; Ap 18:4, 5).

En el día final, "muchos" se perderán porque habrán preferido sus ideas a “la voluntad de Dios”. Jesús dijo: “No todo el que me dice: ‘Señor, Señor!', entrará en el reino de los cielos, sino el que hace la voluntad de mi Padre que está en los cielos. Muchos me dirán en aquel día: 'Señor, Señor, ¿no profetizamos en tu nombre, y en tu nombre echamos fuera demonios, y en tu nombre hicimos muchos milagros?'. Entonces les declararé: 'Nunca os conocí. ¡Apartaos de mí, hacedores de maldad!'” (Mt 7:21-23). La iglesia verdadera es aquella a que obedece a todo lo que Dios ordena en su Palabra (Lc 24:27, 44, 45; Jn 17:17; Hch 17:1-3, 10, 11; 1 Ti 6:3-5; 2 Ti 3:15-17).

\section{SE PREDICE UNA APOSTASÍA EN LA FE CRISTIANA}

Pero, ¿dónde está esa iglesia verdadera en la actualidad? Para responder con claridad debemos empezar entendiendo lo que sucedió en el cristianismo. El que "las puertas del Hades" no iban a prevalecer contra la iglesia no significa que ella no atravesaría por alguna crisis. Al contrario, las fuerzas del mal harían todo lo posible para destruirla. Los apóstoles lo sabían, y por eso predijeron que se iba a producir una apostasía en la fe cristiana. En Hechos 20:28-30 se les pide a los ancianos de la iglesia de Éfeso que cuiden "la iglesia del Señor", porque conocía que después de su partida entrarían "lobos rapaces", y se levantarían hombres que hablarían "cosas perversas". Instando a Timoteo a que predique "la palabra... a tiempo y fuera de tiempo", Pablo le dice "redarguye, reprende, exhorta con toda paciencia y doctrina, pues "vendrá tiempo cuando no soportarán la sana doctrina, sino que, teniendo comezón de oir, se amontonarán maestros conforme a sus propias pasiones, y apartarán de la verdad el oído y se volverán a las fábulas" (2 Ti 4:1-4). 
Esta apostasía no se dio de un momento a otro, fue un proceso gradual que duró siglos. Desde el mismo período apostólico se podían observar fuerzas extrañas tratando de corromper la iglesia (2 P 2:1-3; Jud 1:3, 4). Pablo ya veía en acción "el misterio de la iniquidad" (2 Ts 2:1-7), pero la presencia de la primera generación de cristianos, de alguna manera, frenó el avance de la apostasía religiosa en ese primer siglo. Sin embargo, entre los siglos II y VI, lenta y paulatinamente, se fue configurando el sistema religioso que llegaría a conocerse con el nombre de Roma papal o papado. Durante esos siglos, y en adelante, se fueron introduciendo en el cristianismo doctrinas carentes de base bíblica que caen dentro de la categoría de "fabulas" o "mitos" religiosos. Por ejemplo, la salvación por obras, la veneración a María, el purgatorio, el bautismo infantil, la oración a los santos, el domingo como día de reposo, la exaltación de la iglesia de Roma y su obispo sobre el resto de iglesias, etc. Las profecías de Daniel y Apocalipsis, utilizando los símbolos del “cuerno pequeño" (Dn 7:8, 20-27; 8:1012); "la bestia" (Ap 13:1-10); y "la gran ramera" (Ap 17:1-6), 6 ya anunciaban el aparecimiento de este falso sistema religioso que tiró por tierra la verdad bíblica.

\section{LA IGLESIA EN EL DESIERTO}

Cuando en el siglo VI el papado recibió el apoyo militar de la autoridad civil se convirtió en un poder perseguidor del pueblo de Dios. Una de las profecías que anunciaba las luchas que tenía que atravesar la iglesia a lo largo de la historia, pero de manera especial en el tiempo del fin, se encuentra en Apocalipsis 12.7 En este capítulo la iglesia verdadera es representada por una mujer "vestida del sol" (vv. 1, 2), y el dragón es un símbolo de Satanás (v. 9). Satanás intentó destruir al Salvador durante su ministerio terrenal, pero como no pudo (v. 4, 5), se lanzó en ataque contra la iglesia (v. 13). El versículo 14 afirma que la mujer tuvo que huir al desierto por un periodo de "un tiempo, tiempos y

${ }^{6}$ William H. Shea, Daniel: A Reader's Guide (Nampa, ID: Pacific Press, 2005), 177-183; C. Mervyn Maxwell, God Cares: The Message of Revelation for You and Your Family (Nampa: Pacific Press, 1985), 367, 368.

7Para un estudio de Apocalipsis 12, véase Ranko Stefanovic, La revelación de Jesucristo: comentario del libro del Apocalipsis (Berrien Springs, MI: Andrews University Press, 2013), 383-406. 
la mitad de un tiempo". Así se muestra que el pueblo de Dios tuvo que huir de las persecuciones que Roma papal dirigió contra los cristianos fieles que no reconocían su autoridad.

El periodo mencionado de “tiempo (1 año), tiempos (2 años), y medio tiempo ( $1 \frac{1}{2}$ año)" son 1260 días según el versículo 6. En profecía un día equivale a un año (Nm 14:34; Ez 4:6), ${ }^{8}$ por tanto, estamos frente a 1260 años de predominio papal. Este periodo empezó en el año 538 cuando entró en vigencia el edicto del emperador romano de Oriente Justiniano I (482-565) que declaraba al obispo de Roma "cabeza de todas las santas iglesias", 9 y terminó 1260 años después, en 1798, cuando el obispo de Roma fue llevado al exilio por las tropas francesas. ${ }^{10}$ Durante estos siglos de la Edad Media los verdaderos cristianos no podían adorar en libertad, y se mantenían escondidos en lugares alejados para mantener viva la llama de la verdad. La historia cuenta que el papado persiguió a miles de cristianos como los valdenses y albigenses, pero solo Dios sabe cuántos más sellaron con sus vidas su lealtad a la Palabra de Dios.

\section{EL SURGIMIENTO DE LA}

\section{REFORMA PROTESTANTE Y SU ESTANCAMIENTO}

En el siglo XVI, durante el tiempo de predominio papal, apareció la Reforma protestante con el propósito de reformar el cristianismo. La Reforma enfatizó el principio de la sola Scriptura, contra la idea romana de la interpretación de la Escritura junto con la tradición. Destacó el principio de la sola gracia, en contra de la salvación por gracia más obras meritorias. Resaltó el principio de solo Christo contra la idea papal de que además de Cristo se necesitaban otros mediadores, como los sacerdotes y los santos en el cielo. Pero el mayor logro de

8Para una explicación, interpretación y validación del principio "día por año", véase William H. Shea, Selected Studies on Prophetic Interpretation, Daniel \& Revelation Committee Series (Washington, DC: Review and Herald Publishing Association, 1982), 1:56-93; Gerhard Pfandl, "In Defense of the Year-day Principle", Journal of the Adventist Theological Society, 23/1 (2012):3-17.

${ }^{9}$ Alberto R. Timm, "A importância das datas de 508 e 538 d.C. para a supremacia papal", Revista Parousia 4, n. 1, (2005): 7-18.

10Para un estudio de estos periodos proféticos, véase William H. Shea, "Times Prophecies of Daniel 12 and Revelation 12-13", en Symposium on Revelation, ed., Frank Holbrook (Silver Spring, MD: Biblical Research Institute, 2000), 1:327-360. 
la Reforma fue devolver las Escrituras a las manos de las personas y en idiomas que el pueblo entendía. Eso permitió que las personas pudiesen tener acceso al conocimiento de Dios por sí mismos. Lamentablemente la Reforma protestante se estancó, pues no avanzó más allá de donde sus líderes iniciales la habían llevado. Por eso, el movimiento se dispersó en diferentes denominaciones y no logró progresar en el redescubrimiento de más verdades bíblicas, ni pudo desprenderse de falsas doctrinas como la inmortalidad del alma, el domingo como día de reposo, entre otros errores.

\section{DIOS LEVANTA SU REMANENTE}

Después de haber perseguido al pueblo de Dios a lo largo de la historia, Apocalipsis 12:17 presenta a Satanás lanzando el último ataque contra el pueblo de Dios del tiempo final: "Entonces el dragón se llenó de ira contra la mujer y se fue a hacer la guerra contra el resto de la descendencia de ella, contra los que guardan los mandamientos de Dios y tienen el testimonio de Jesucristo". Aquí se muestra que después del periodo de 1260 años de predominio papal (538-1798), Dios tendría un "resto" de la mujer al que el diablo le haría la guerra. Es decir, del pueblo de Dios a lo largo de los siglos ha sobrevivido en el tiempo final un remanente que permanece leal a la Palabra de Dios. ¿Cómo identificar ese remanente? El texto identifica a este remanente por dos características: (1) "los que guardan los mandamientos de Dios", y (2) “tienen el testimonio de Jesús".

La primera característica indica que ellos entienden que al ser salvos por gracia (Ef 2:8, 9) obedecen por amor los mandamientos divinos, incluyendo el cuarto que enseña que el sábado es el día de reposo (Ex 20:1-17). Hay denominaciones religiosas que afirman ser este remanente, pero enseñan que no hay necesidad de guardar los mandamientos porque Jesús ya los abolió en la cruz. Otras dicen que hay que observarlos, pero han cambiado el mandamiento del sábado por el domingo ¿Pueden ser esos grupos la iglesia verdadera? ¡Claro que no! La evidencia bíblica establece que el verdadero pueblo de Dios será fiel a toda la ley divina y no a una parte de ella (Jn 14:15; Ro 3:31; 7:7, 12; Stg 2:1012; 1 Jn 2:3-6; Ap 14:12). 
La segunda característica es que "tienen el testimonio de Jesús". ¿Qué significa esto? La frase aparece en otras partes de Apocalipsis, en las que se refiere al "testimonio", o mensaje que proviene de Jesús y que se entrega a las personas por el conducto de algún profeta (Ap 1:1, 2, 9; 22:20). Esto queda corroborado por Apocalipsis 19:10 que denomina al "testimonio de Jesús" "el espíritu de la profecía". El "espíritu de la profecía" es otra forma de hablar del don profético. Esto queda más que claro cuando se compara Apocalipsis 19:10 con 22:9. En el primer pasaje el ángel declara que es "consiervo" de Juan y de sus "hermanos que retienen el testimonio de Jesús", y en el segundo pasaje a estos "hermanos" de Juan el ángel los llama "los profetas". Son los profetas quienes reciben "el testimonio de Jesús" para entregarlo al pueblo. En otras palabras, el remanente del tiempo final tendría la presencia del don profético en sus filas.

Por todo lo anterior, los adventistas del séptimo día no tienen dudas de su identidad como el pueblo remanente de la profecía. Dios los levantó después de 1798 como una continuación de la iglesia histórica, creen en Jesús como su Salvador, aceptan la Biblia como su única guía, defienden la vigencia de todos los mandamientos, incluyendo el sábado, y entre ellos se ha manifestado el don profético. Los adventistas no se sienten superiores a otros, pero por amor a Cristo han decidido permanecer fieles a la verdad en medio de la apostasía generalizada. También entienden que han sido llamados por Dios para continuar la reforma que se estancó y extender el último llamado de misericordia al mundo, contenido en el triple mensaje angélico (Ap 14:6-12). El pueblo adventista sabe que en cada grupo religioso existen personas sinceras, y por eso las invita a investigar personalmente la Escritura, a salir del error y abrazar la verdad, antes de que sea tarde (Ap 14:14-16). Si aún no forma parte de este movimiento profético, únase a él, y prepárese para recibir a Jesús cuando vuelva "en las nubes del cielo, con poder y gran gloria" (Mt 24:30). 